City University of New York (CUNY) CUNY Academic Works

2019

\title{
Burnout: Moving Beyond the Status Quo
}

Renzo Bianchi

Université de Neuchâtel

Irvin Sam Schonfeld

CUNY Graduate Center

Éric Laurent

Université Bourgogne Franche-Comté

\section{How does access to this work benefit you? Let us know!}

More information about this work at: https://academicworks.cuny.edu/gc_pubs/525

Discover additional works at: https://academicworks.cuny.edu

This work is made publicly available by the City University of New York (CUNY).

Contact: AcademicWorks@cuny.edu 


\title{
Burnout: Moving Beyond the Status Quo
}

\author{
Renzo Bianchi \\ University of Neuchâtel
}

\author{
Irvin Sam Schonfeld \\ The City College of the City University of New York
}

\author{
Eric Laurent \\ Bourgogne Franche-Comté University
}

\begin{abstract}
Burnout has been defined as a job-induced syndrome combining emotional exhaustion, depersonalization/cynicism, and a sense of reduced personal accomplishment. In this article, we expand on past analyses of burnout by reviewing key, yet overlooked, problems affecting the construct. We concomitantly examine the implications of these problems for the overall validity of burnout research. Our work shows that burnout research is undermined by 4 main problems. First, what constitutes a case of burnout is unclear. Second, the basic conceptualization and operationalization of burnout are ill aligned. Third, burnout is unlikely to be the specifically job-induced syndrome it has been posited to be. Fourth, the discriminant validity of the burnout construct is unsatisfactory. These fundamental problems, disregarded for decades, render burnout research inconclusive. This state of affairs (a) bears on researchers' and practitioners' ability to monitor and protect workers' health and (b) prevents public health policymakers from producing authoritative recommendations. The burnout construct thus appears to not well serve the goal of promoting occupational health. The depression construct may offer occupational health specialists a way out of the "burnout impasse." Depression is diagnosable. Like burnout, depression can be studied dimensionally (i.e., as a process) and examined from both an individual and a social standpoint. Methods for investigating the etiological link between depressive symptoms and disorders and job stress are available.
\end{abstract}

Keywords: burnout, depression, measurement, methodology, occupational health

First described in psychology in the 1970s (Freudenberger, 1974; Maslach, 1976), burnout has since been commonly regarded as a job-induced syndrome involving emotional exhaustion, depersonalization/cynicism, and a sense of reduced personal accomplishment (Maslach, Schaufeli, \& Leiter, 2001; Schaufeli \& Enzmann, 1998). Of the three components of burnout, (emotional) exhaustion has been considered the core of the syndrome (Schaufeli, 2017). Maslach et al. (2001) underlined that "exhaustion is the central quality of burnout and the most obvious manifestation of this complex syndrome" and that it is "the most widely reported and the most thoroughly analyzed" (pp. 402-403) component of burnout syndrome (see also Cox, Tisserand, \& Taris, 2005; Schaufeli, 2017). Maslach and Leiter (2010) indicated, in a recent review of burnout research, that "exhaustion is . . more predictive of stress-related health outcomes than the other two components [of burnout]" (p. 726).

This article was published Online First December 28, 2017.

Renzo Bianchi, Institute of Work and Organizational Psychology, University of Neuchâtel; Irvin Sam Schonfeld, Department of Psychology, The City College of the City University of New York; Eric Laurent, Department of Psychology, Bourgogne Franche-Comté University.

We thank Takayuki Dohi for his inspiring reflections on burnout.

Correspondence concerning this article should be addressed to Renzo Bianchi, Institute of Work and Organizational Psychology, University of Neuchâtel, Émile-Argand 11, 2000 Neuchâtel, Canton of Neuchâtel, Switzerland. E-mail: renzo.bianchi@unine.ch
The three dimensions of burnout come from, and are assessed with, the Maslach Burnout Inventory (MBI), a self-administered questionnaire introduced in the early 1980s (Maslach \& Jackson, 1981; Maslach et al., 2001). The MBI was designed based on data collected through exploratory interviews, case studies, field observations, and personal experiences during the early phases of burnout research (Leiter \& Maslach, 2016; Schaufeli \& Enzmann, 1998). Although its development was neither clinically grounded nor theory driven, the MBI has been, by far, the most widely used measure of burnout (Schaufeli \& Enzmann, 1998; Schaufeli, Leiter, \& Maslach, 2009; Shirom, 2005). The MBI has critically influenced the growth of the entire field of burnout research (Bianchi, Schonfeld, \& Laurent, 2015b).

Today, burnout is a well-implanted construct in occupational health research. As we are writing these lines, the keyword burnout generates about 12,000 hits in search engines such as PsycINFO and PubMed. The keen interest in burnout, however, has coexisted with persistent difficulties in characterizing the phenomenon. Thus, more than 30 years after the emergence of the burnout construct, Shirom (2005) invited burnout researchers to "begin with a clear definition of the construct of burnout" (p. 268). Contemporaneously, Cox et al. (2005) regretted that burnout researchers still had to deal with basic definitional and measurement issues regarding their entity of interest: “. . . despite the large number of scientific papers published on burnout, we have not yet convincingly answered many of the long-standing questions. This must be a concern to all occupational health psychologists" ( $\mathrm{p}$. 189). 
In this article, we review major, yet overlooked, problems affecting the burnout construct and examine how these problems bear on the overall validity of burnout research. More specifically, we address the questions of (a) the diagnosis and prevalence of the burnout syndrome, (b) the consistency of the conceptualization and operationalization of the burnout construct, (c) the etiology of the burnout syndrome, and (d) the discriminant validity of the burnout construct. Our analysis of burnout research leads us to envisage two interrelated paths to action for more effectively dealing with the issue of unresolvable job stress: (a) shifting the focus of occupational health research from burnout to job-related depression and (b) reinforcing initiatives aimed at reducing depressionrelated stigma.

\section{The Problem of Diagnosis and Prevalence of Burnout}

Although some authors have claimed that burnout has reached epidemic levels, for instance among physicians (West, Dyrbye, Erwin, \& Shanafelt, 2016), it has been observed that the prevalence of burnout cannot be estimated for the basic reason that burnout is not diagnosable (Bianchi, Schonfeld, \& Laurent, 2015a; Bianchi, Schonfeld, Vandel, \& Laurent, 2017; Doulougeri, Georganta, \& Montgomery, 2016). Indeed, notwithstanding decades of sustained research, and the supposed ubiquity of the syndrome, there has been thus far no clear and consensual specification of (a) the symptoms to be considered in clinical assessments of burnout, (b) the minimal required duration and frequency of these symptoms, (c) the expected impact of the exhibited symptoms on the patient's (work) life, or (d) differential diagnosis procedures. As underscored in past research, the published estimates of prevalence of burnout have relied on heterogeneous criteria that were neither clinically nor theoretically founded (Bianchi, 2015; Bianchi, Schonfeld, \& Laurent, 2017d; Schears, 2017). Contemporary studies of medical professionals illustrate the malleability of prevalence estimates for burnout. For instance, Garrouste-Orgeas et al. (2015) found that, depending on how burnout was defined, the prevalence of burnout in a sample of intensive care unit professionals varied from $3 \%$ to $40 \%$. Likewise, in a study of U.S. general surgery trainees (Elmore, Jeffe, Jin, Awad, \& Turnbull, 2016), burnout was found to have a prevalence of either $10 \%$ or $69 \%$ depending on the retained definition. Balon (2017) summarized the current situation in the following terms: "Numerous studies keep showing ever-increasing rates [of burnout] without any substantial debate about what these numbers mean and how we should interpret them" (p. 82).

A common practice in burnout research consisted of using the cutoff scores presented in the MBI manual (Maslach, Jackson, \& Leiter, 1996) as identifiers of "cases" of burnout. These cutoff scores, however, reflect mere descriptive statistics-a tercile-based split-and were not intended to be used for the purpose of arriving at a diagnosis (Maslach et al., 1996). As put by Schaufeli et al. (2009),

\footnotetext{
... such cutoffs are based on frequency distributions and therefore do not refer to an external criterion. For example, a score at the 70th percentile on exhaustion is relatively high, but it may not be associated with subjective distress, health disorders, or poor performance. (p. 212)
}

A related problem is that a tercile-based split is sample dependent. Consequently, falling in the third tercile may not mean the same thing at all as a function of the distribution of interest (Lehr, Koch, \& Hillert, 2010).

The use of arbitrary identification criteria in burnout research carries the triple risk of (a) pathologizing ordinary fluctuations in daily levels of stress, fatigue, or motivation; (b) undermining the identification of respondents who may, indeed, need help by drowning them in a sea of heterogeneous health conditions; and (c) trapping investigators in endless speculations regarding the widespreadness of the burnout syndrome. In effect, the reliance on categorization criteria that have no clinical or theoretical foundation allows virtually any conclusion to be reached-from the most reassuring to the most alarming - regarding the health status of surveyed workers (Bianchi et al., 2015a). Because any conclusion is synonymous with no conclusion, the recommendations for organizational/institutional changes derived from the findings of burnout research (Epstein \& Privitera, 2016) can be easily challenged by anyone willing to reject them (Bianchi, Schonfeld, \& Laurent, 2016b, 2017d). The use of arbitrary identification criteria in burnout research thus impedes public health action (Bianchi, Schonfeld, \& Laurent, 2016a).

\section{Conceptual and Operational Inconsistencies and Ambiguities}

A close examination of the literature dedicated to burnout reveals that the absence of a nosological characterization of burnout is only the tip of the iceberg. The basic conceptualization and operationalization of burnout are themselves unclear (Kristensen, Borritz, Villadsen, \& Christensen, 2005). Burnout has been assumed to be a three-component syndrome combining emotional exhaustion, depersonalization, and reduced personal accomplishment (Maslach et al., 1996; Schaufeli \& Enzmann, 1998). However, in contravention of this assumption, it has been formally recommended that the three components of burnout be examined individually. Maslach et al. (1996) thus wrote in the manual of the MBI: ". . . the scores for each subscale are considered separately and are not combined into a single, total score. Thus, three scores are computed for each respondent" (p. 5). This recommendation has led many burnout researchers to regard individuals as "burned out" on the basis of their reaching a threshold score on only one of the three subscales of the MBI (Elmore et al., 2016; Shanafelt et al., 2015). Such research practices have been questioned because they imply that individuals who suffer only from emotional exhaustion, only from depersonalization, or only from reduced personal accomplishment will be considered as suffering from the same condition, namely, "burnout," though they present with symptom profiles that are, by definition, different and potentially call for different management strategies (Brisson \& Bianchi, 2017). Such research practices are also inconsistent with Maslach et al.'s (2001) observation that "exhaustion is a necessary criterion for burnout" (p. 403) as well as with the supposed coexistence of emotional exhaustion and depersonalization in full-blown burnout (Maslach \& Leiter, 2008).

It is worth dwelling on depersonalization for a moment. In effect, the spotlighting of this component of burnout in certain areas of burnout research (Orton, Orton, \& Pereira Gray, 2012) may be partly misleading. The flourishing area of physician burnout research is particularly relevant in this respect. Affirmative responses to items of the MBI Depersonalization subscale such as 
"I've become more callous toward people since I took this job" may be indicative of distance-based coping strategies that are normal in medical settings, rather than symptomatic of a pathogenic form of cynicism. Physicians need to establish and maintain a balance between distance and empathy to be effective while protecting themselves from potential stressors that their job entails. Thus, some degree of distance is not necessarily reflective of an indifferent, careless form of cynicism and does not necessarily constitute a threat to either physicians' or patients' health. As noted by Rose, Duschinsky, and Macnaughton (2017), "tempered cynicism can protect the inner core of care and good practice" (p. 693). This kind of tempered cynicism (e.g., educational desensitization) is seen as protective in other health professionals such as emergency medical technicians, who often encounter gruesome injuries in the course of their job (Palmer, 1983). The ambiguity of the depersonalization component of burnout may account, for instance, for findings of Orton et al. (2012) that depersonalization was not associated with poorer patient ratings of doctors' interpersonal skills or a reduction in the patient centeredness during consultations.

The Depersonalization subscale of the MBI involves other forms of ambiguity. Here too, the research dedicated to physician burnout can be usefully mobilized. For instance, an item such as "I feel patients blame me for some of their problems" may not always implicate depersonalization. An affirmative response to such an item may reflect an accurate judgment. Physicians who were indeed blamed for some of their patients' problems may accurately report that they were. Physicians are sometimes blamed for some of their patients' problems (either justifiably or unjustifiably); this is an observed fact. Given that the Depersonalization subscale of the MBI contains only five items, ambiguity in even one item is likely to significantly bear on (a) the subscale's internal consistency and (b) how the physician's responses can be interpreted. As suggested by Schaufeli and Enzmann (1998), "the occasional low internal consistencies for depersonalisation are not only due to the small number of items, as is usually assumed, but may also reflect conceptual problems" (p. 51). The shortcomings attached to the Depersonalization subscale of the MBI may partly explain why Taris (2006), in a meta-analysis of 16 studies, did not find conclusive evidence that depersonalization is negatively associated with objective performance on the job. In the next section, we turn to the issue of the link between work stress and burnout.

\section{The Unclear Etiology of Burnout}

Often taken for granted, the link between work stress and burnout has itself been shown to be open to question (Hakanen \& Bakker, 2017). Although burnout has been conceived of as a job-induced syndrome, the most widely used measure of burnout, the MBI (Maslach et al., 1996), actually provides limited information on the etiology of the symptoms it is intended to assess. MBI items such as "I feel like I'm at the end of my rope" or "I feel very energetic" are generic in nature. Moreover, it should be underscored that an individual can feel stressed (out) at work for reasons that are not initially or primarily related to his or her job (e.g., conjugal or familial problems). Thus, the exact involvement of work in the emergence of symptoms self-reported through the MBI is difficult to estimate. The blur surrounding the etiology of the symptoms assessed by the MBI may partly account for the difficulties in designing effective interventions to (a) alleviate burnout symptoms and (b) support the return to work of individuals on sick leave (Ahola, Toppinen-Tanner, \& Seppänen, 2017; Dreison et al., 2016; Maricuţoiu, Sava, \& Butta, 2016; Panagioti et al., 2017). Interventions focusing exclusively on work may not be sufficient if the individual's symptoms originate in personal (i.e., job-unrelated) problems. Research examining the variance in MBI scores respectively explained by work and nonwork stressors would be needed to clarify the question.

Hakanen and Bakker (2017) argued that the ignorance of nonwork factors in burnout research has prevented us from determining what kind of ill-being and suffering is assessed by burnout measures. Interestingly, these authors cited the results of an interview-based study (published in Finnish), suggesting that individuals with relatively high levels of burnout symptoms typically have problems both at work and at home. Similar results were obtained in another qualitative study, conducted in South Africa, in which the authors found that burnout is a multidomain phenomenon (Gauche, de Beer, \& Brink, 2017). In a recent study carried out in Switzerland and involving 468 health professionals, only $44 \%$ of the participants with burnout symptoms considered their job to be the main cause of these symptoms (Bianchi \& Brisson, in press). Taken together, these observations suggest that recommendations for work-centered interventions cannot be straightforwardly derived from data collected with burnout measures. The problem raised here is of great concern given that the utility of burnout has been, to a considerable extent, linked to the ability of the construct to specifically capture work-induced ill-being and suffering (Maslach et al., 2001; Shirom, 2005).

\section{The Burnout Construct's Lack of Discriminant Validity}

To be considered valid, a construct needs to show convergent and discriminant validity, both conceptually and empirically (Campbell \& Fiske, 1959; Cronbach \& Meehl, 1955; Le, Schmidt, Harter, \& Lauver, 2010). Although there is evidence of the convergent validity of the burnout construct (Halbesleben \& Demerouti, 2005; Qiao \& Schaufeli, 2011; Winwood \& Winefield, 2004), the discriminant validity of the burnout construct has been found to be unsatisfactory, most notably with respect to depression.

\section{Conceptual Examination of the Burnout Construct's Discriminant Validity}

As previously mentioned, burnout has been commonly viewed as a combination of emotional exhaustion, depersonalization/cynicism, and diminished personal accomplishment (Maslach et al., 2001). The question of whether the components of burnout refer to depressive symptoms under nonmedical labels has raised growing concerns in recent years (Bianchi, Schonfeld, \& Laurent, 2017a, 2017c; Schonfeld, Laurent, \& Bianchi, 2017).

Emotional exhaustion, the main component of burnout, is assessed with items such as "I feel fatigued when I get up in the morning and have to face another day on the job" and "I feel like I'm at the end of my rope" (Maslach et al., 1996). Such items are indicative of fatigue/loss of energy, depressed mood, and possibly sleep disturbance, three diagnostic criteria for major depressive disorder (American Psychiatric Association, 2013). Interestingly, 
the Diagnostic and Statistical Manual of Mental Disorders, Fifth Edition (DSM-5) mentions that fatigue is often the presenting complaint in depressed individuals (American Psychiatric Association, 2013).

Depersonalization/cynicism has sometimes been thought to constitute a clearly distinguishing feature of burnout. However, items such as "I have become less interested in my work since I started this job" or "I don't really care what happens to some recipients" (Maslach et al., 1996) actually refer to symptoms that are commonly found in depression, namely, loss of emotional involvement, withdrawal, and loss of interest (American Psychiatric Association, 2013; Beck \& Alford, 2009). Loss of enjoyment in activities that were previously considered pleasurable and "not caring anymore" are well-known characteristics of depression (American Psychiatric Association, 2013, p. 163). Depersonalization/cynicism also involves irritability, as illustrated by the MBIGeneral Survey item "I just want to do my job and not be bothered" (Maslach et al., 1996). The DSM-5 stipulates (American Psychiatric Association, 2013) that "many [depressed] individuals report or exhibit increased irritability (e.g., persistent anger, a tendency to respond to events with angry outbursts or blaming others, an exaggerated sense of frustration over minor matters)" (p. 163). Judd, Schettler, Coryell, Akiskal, and Fiedorowicz (2013) even found that irritability/anger during major depressive episodes was a clinical marker of a more severe, chronic, and complex depressive illness. In depression, irritability often masks sadness, especially in younger and male individuals (American Psychiatric Association, 2013; Martin, Neighbors, \& Griffith, 2013). Consistent with this finding, men have been repeatedly found to show higher levels of depersonalization/cynicism than women (Maslach et al., 2001).

Diminished personal accomplishment, the third component of burnout, refers to negative self-evaluation and feelings of failure in the job (Maslach et al., 1996). Again, such feelings are symptomatic of depression. Feelings of worthlessness constitute a diagnostic criterion of major depressive disorder (American Psychiatric Association, 2013). Low self-esteem and the belief that one is unable to deal with the adversity encountered (at work or elsewhere) are hallmarks of depression (Beck \& Alford, 2009).

That the three components of burnout are reflective of depressive symptoms raises a concern regarding the discriminant validity of the burnout construct vis-à-vis the depression construct. The definitional overlap between burnout and depressive symptoms may reflect the jangle fallacy, "the assumption that two constructs are dissimilar simply because they have different names" (Fogarty \& Perera, 2016, pp. 422-423). This phenomenon, widespread in psychology, is likely to occur when a "new" construct is introduced in the literature without a careful examination of, and contextualization within, the related preexisting literature (see Fogarty \& Perera, 2016; see also Le et al., 2010). Interestingly, the initial publications on burnout (Freudenberger, 1974; Maslach, 1976) did not include any comprehensive review of the literature dedicated to already-described stress-related conditions such as depressive conditions.

Another source of concern regarding the distinctiveness of burnout has been attributed to the (presumed) etiology of the syndrome. In effect, unresolvable stress, which is thought to play a causative role in the development of burnout (Maslach et al., 2001; Shirom,
2005), is known to be central in the etiology of depression (Ilardi, 2009; McEwen, 2004; Pizzagalli, 2014; Pryce et al., 2011; Willner, Scheel-Krüger, \& Belzung, 2013). There is a strong evidence base, from research conducted in psychiatry, behavioral psychology, and neurobiology, that depressive symptoms constitute basic responses to unresolvable stress (either job related or not) in individuals with no noticeable susceptibility to depression (Willner et al., 2013; see also Breier et al., 1987; Laborit, 1986; Nesse, 2000; Seligman, 1975).

Occupational adversity has been specifically identified as a predictor of depressive symptoms and disorders in numerous studies (Melchior et al., 2007; Niedhammer, Malard, \& Chastang, 2015; Schonfeld, 2001; Wang, Patten, Currie, Sareen, \& Schmitz, 2012). In a recent survey involving 3,021 medical interns (Fried, Nesse, Guille, \& Sen, 2015), all nine symptoms of major depression (American Psychiatric Association, 2013) were found to increase-on average by $173 \%$ - in response to the stress of medical internship over a period of about 1 year. As underlined by Pizzagalli (2014),

although severe stressors have been generally linked to increased risk of depression, chronic stressors and events characterized by perceived (a) lack of control, (b) inability to escape or resolve the aversive situation (e.g., entrapment), or (c) loss of status (e.g., humiliation) appear to be particularly depressogenic. (p. 406)

Such depressogenic factors are at stake in the occupational sphere and have all been thought to contribute to burnout under one form or another (Maslach et al., 2001; Schaufeli \& Enzmann, 1998).

From a conceptual standpoint, the discriminant validity of the burnout construct is thus unclear. Not only the symptoms defining burnout but also the etiology imputed to the syndrome is evocative of depression. Despite these similarities, objections to the idea that burnout is a depressive condition have been recurrently raised by some of the main contributors to the development of the burnout construct. Maslach et al. (2001) thus argued,

\footnotetext{
... support for this distinction [between burnout and depression] comes from an analysis of various conceptualizations of burnout, which notes five common elements of the burnout phenomenon ... (a) There is a predominance of dysphoric symptoms such as mental or emotional exhaustion, fatigue, and depression. (b) The emphasis is on mental and behavioral symptoms more than physical ones. (c) Burnout symptoms are work-related. (d) The symptoms manifest themselves in "normal" persons who did not suffer from psychopathology before. (e) Decreased effectiveness and work performance occur because of negative attitudes and behaviors. (p. 404)
}

Given their considerable influence in the field of burnout research, the five arguments raised by Maslach et al. (2001) call for discussion. Do these five justifications of the burnout-depression distinction stand up to scrutiny? In our estimation, the answer to this question is negative.

First, the claim that burnout differs from depression in that burnout predominantly involves dysphoric symptoms is not admissible given that dysphoria is an integral part of depressive symptomatology (Beck \& Alford, 2009; Sapolsky, 2004). According to the DSM-5, dysphoria (or dysphoric mood) refers to "a condition in which a person experiences intense feelings of depression, discontent, and in some cases indifference to the world around them" (American Psychiatric Association, 2013, p. 821). Dyspho- 
ria is typically assessed with depressive symptom scales (Bradley, Mogg, \& Lee, 1997; Caseras, Garner, Bradley, \& Mogg, 2007; Strack \& Coyne, 1983). The term dysphoria is in fact commonly used in studies in which (a) depressive symptoms are assessed with self-report measures rather than structured clinical interviews and (b) the investigator wants to refer to subclinical, in contrast with clinical, depression (Gotlib, Yue, \& Joormann, 2005; Martin, Blum, Beach, \& Roman, 1996; Matheson \& Anisman, 2003; Roberts, Gilboa, \& Gotlib, 1998). Moreover, Maslach et al. (2001) explicitly mentioned that the predominance of depression in burnout is a characteristic that distinguishes burnout from depression. This statement is self-contradictory and, therefore, self-invalidating.

Second, the mental and behavioral manifestations of depression have been studied in detail for decades (Beck \& Alford, 2009). As an illustration, behavioral activation method and cognitivebehavioral therapy count among the most widely used and effective treatments for depression (Cuijpers, van Straten, \& Warmerdam, 2007; Richards et al., 2016). The idea that the emphasis in depression research would be placed on so-called physical symptoms overstates the case.

Third, the claim that burnout differs from depression in that burnout is work related is problematic because of the following reasons: (a) depression can also be work related, (b) the workrelated character of a syndrome is not nosologically discriminant per se-a work-related depression remains a depression, and (c) the idea that the burnout phenomenon is restricted to work is logically specious-there is no reason to think that emotional exhaustion, depersonalization, and loss of personal accomplishment could not be elicited by nonoccupational factors or develop in nonoccupational contexts (Bianchi, Schonfeld, \& Laurent, 2015d; Bianchi, Truchot, Laurent, Brisson, \& Schonfeld, 2014; Hallsten, Josephson, \& Torgén, 2005; Kristensen et al., 2005; Pines, 1987).

Fourth, the assumption that burnout symptoms manifest themselves in "normal" persons who did not suffer from psychopathology before has been shown to be misleading. Antecedents of mood and anxiety disorders, for instance, have been linked to burnout in several studies (Bianchi, Schonfeld, \& Laurent, 2014; Rössler, Hengartner, Ajdacic-Gross, \& Angst, 2015; Schonfeld \& Bianchi, 2016). Moreover, although past psychopathology is a risk factor for future psychopathology, an individual can experience a depressive episode at some point in his or her life without having a history of psychopathology (Dohrenwend, 1979).

Fifth, there is no reason to consider that decreased effectiveness and impaired work performance could not occur because of negative attitudes and behaviors in depression just as in burnout. An individual with a job-induced depressive condition may show decreased effectiveness and impaired work performance because he or she has developed negative attitudes and behaviors based on his or her stressful experiences in the job (Beck \& Alford, 2009). ${ }^{1}$

In sum, the five arguments formulated by Maslach et al. (2001) do not justify a distinction between burnout and depression. Paradoxically, these arguments, most notably the "dysphoria argument," turn against the assumption they were supposed to support when closely examined.

\section{Empirical Examination of the Burnout Construct's Discriminant Validity}

Associations between burnout and depressive symptoms. Burnout has been associated with all "classical" symptoms of depression, including the most emblematic and severe, such as depressed mood, anhedonia, and suicidal ideation (Bianchi et al., 2014; Schonfeld \& Bianchi, 2016). Burnout and depressive symptoms have been observed to cluster together and increase or decrease commensurately over time (Ahola, Hakanen, Perhoniemi, \& Mutanen, 2014; Bianchi, Schonfeld, \& Laurent, 2015c). Bianchi et al. (2014) found that $90 \%$ of the individuals experiencing burnout symptoms at least a few times a week (as assessed by the MBI) met criteria for a provisional diagnosis of depression (as established by the 9-item depression module of the Patient Health Questionnaire [PHQ-9]; Kroenke \& Spitzer, 2002). In numerous studies (for a review, see Bianchi et al., 2015b), emotional exhaustion - the core of burnout— has been observed to be more strongly associated with "classical" depressive symptoms than with the two other definitional dimensions of burnout (depersonalization/cynicism and reduced personal accomplishment). Bearing in mind that a syndrome refers to a constellation of concomitant symptoms (Shirom, 2005), this recurrent finding tends to suggest that "classical" depressive symptoms constitute the heart of burnout (see also Hallsten et al., 2005). The empirical overlap of burnout and depressive symptoms is consistent with the fact that burnout is often treated as a depressive syndrome in clinical practice. In a study of 3,276 Finnish employees, Ahola et al. (2007) found that antidepressant prescriptions were about 14 times more common among individuals with so-called severe burnout ${ }^{2}$ than among individuals with no noticeable symptoms of burnout, adjusting for gender, age, marital status, and occupational grade.

Evidence from factor analytic research. The view that burnout is distinct from depression has strongly relied on the finding that burnout and depression loaded on different factors when self-reported measures of burnout and depression were submitted to factor analyses (Maslach et al., 2001). Thus, in one of the most influential studies in this research area, Leiter and Durup (1994) concluded that burnout and depression were best modeled as two second-order factors-while acknowledging the strong correlation (.72) between these factors. The study, however, had important limitations, such as the poor fit of the constructed models or the assessment of burnout and depressive symptoms within different time windows - 1 year for burnout symptoms versus (at most) 2 weeks for depressive symptoms.

In a recent study that aimed at overcoming the limitations of past factor analytic studies of burnout and depression measures by using more sophisticated modeling techniques (Kim \& Eaton, 2015; Marsh, Morin, Parker, \& Kaur, 2014), Schonfeld, Verkuilen, and Bianchi (2017) assessed burnout with the MBI, and depression with both the PHQ-9 and the 10-item version of the Center for Epidemiologic Studies Depression Scale. The study involved 734

\footnotetext{
${ }^{1}$ This being mentioned, it is theoretically likely that the relationships between decreased effectiveness and impaired work performance and negative attitudes and behaviors are causally circular and imply reciprocal effects.

2 In Ahola et al.'s (2007) study, "severe burnout" was defined by a cutoff score of $3.5 / 6.0$ on a the MBI-General Survey.
} 
participants. The results of an exploratory structural equation modeling factor analysis indicated that the items of (a) the MBI's Emotional Exhaustion subscale, (b) the PHQ-9, and (c) the Center for Epidemiologic Studies Depression Scale substantially loaded on the first factor - the factor that explained most of the variance. ${ }^{3}$ In another look at the same data, a confirmatory factor analysis that controlled for measurement error and (potential) item overlap revealed a high correlation (.85) between latent depression and latent emotional exhaustion, suggesting that the two dimensions were reflective of the same underlying construct. The factor analytic evidence thus indicates that the "central quality of burnout" (Maslach et al., 2001, p. 402), emotional exhaustion, is reflective of depression when depression is treated as a dimensional variable.

Biological investigation of the burnout-depression distinction. Biological research has been used with the intention of finding out whether and how burnout differed from depression. A variety of stress-influenced variables have been examined, such as heart rate variability, brain-derived neurotrophic factor, and hippocampal volume (Orosz et al., 2017). No consistent evidence of the distinctiveness of burnout has emerged from this area of research, a state of affairs largely imputed to the methodological heterogeneity of the conducted studies (Danhof-Pont, van Veen, \& Zitman, 2011).

Beyond the question of the specificities or limitations of one study or another, it is crucial to note that biological research on burnout-depression overlap has been rendered fundamentally inconclusive by the nonconsideration of depression subtypes in the conducted studies. ${ }^{4}$ Considering depression subtypes is indispensable in biological research on burnout and depression because different depression subtypes, such as depression with melancholic features and depression with atypical features, have been linked to opposite autonomic (e.g., increased vs. decreased sympathetic activity), endocrine (e.g., hyper- vs. hypocortisolism), and immune profiles (Gold \& Chrousos, 2002; Lamers et al., 2013).

\section{Conclusion on the Discriminant Validity of the Burnout Construct}

All in all, it seems fair to conclude that the discriminant validity of the burnout construct is not satisfactory. Conceptual and empirical examinations converge to suggest that the symptoms and etiology of burnout overlap with the symptoms and etiology of depression. On this basis, and in light of the other major problems undermining the burnout construct, the question of whether occupational health specialists should shift their focus from burnout to job-related depression can be asked. In contrast to burnout, depression, in its various forms (e.g., persistent depressive disorder and major depressive disorder; American Psychiatric Association, 2013), is diagnosable. Therefore, the prevalence of depression can be estimated. Epidemiological evidence can inform public health decision-makers and help them establish action priorities in a context of limited interventional resources. Like burnout, depression can be examined from both an individual and a social standpoint (Bianchi, Schonfeld, \& Laurent, 2017b; Brown \& Harris, 1978; Gilbert, 2006) and studied dimensionally (i.e., as a process) - as empirically evidenced by recent taxometric research (Haslam, Holland, \& Kuppens, 2012; Liu, 2016; Prisciandaro \& Tolliver, 2015). Burnout has been conceived of as a job-induced syndrome. Methods for investigating the etiological link between job stress and depressive symptoms and disorders are available (Bianchi, Schonfeld, Vandel, et al., 2017). Finally, measures of depression (e.g., the PHQ-9 or the Beck Depression Inventory-II) offer access to urgency indicators of workers' suffering such as suicidal ideation. These key indicators are neglected by measures of burnout.

\section{Addressing the Issue of Illness Stigma}

Before closing this article, we briefly turn to the issue of illness stigma, an issue that has been raised in the debate regarding the use of the burnout and depression constructs. This issue is particularly worth considering when envisaging a shift in focus from burnout to job-related depression. In clinical practice, burnout has sometimes been regarded as a helpful euphemism for depression, allowing for a less stigmatizing labeling of depressed patients. Although the question of whether burnout is a less stigmatizing label than depression has not been conclusively answered yet (Bianchi, Verkuilen, Brisson, Schonfeld, \& Laurent, 2016), a problem attached to depression is indeed stigma - an obstacle to help seeking (Boerema et al., 2016; Center et al., 2003; Gold, Andrew, Goldman, \& Schwenk, 2016). Contextual models of stigma reduction for depression, by emphasizing the role of complicated life stressors (e.g., occupational stressors) in the development of depression, offer promising solutions for encouraging depressed individuals to seek help (Rusch, Kanter, \& Brondino, 2009). Interestingly, in a recent interview-based survey $(N=$ 1,600), about eight of 10 participants considered work stress a possible cause of depression-the study sample was representative of the general adult population of France in terms of place of residence, gender, age, and family status (Angermeyer, Millier, Rémuzat, Refaï, \& Toumi, 2013). Such findings are auspicious as far as social representations of depression are concerned.

\section{General Conclusion}

Although combatting unresolvable job stress is a central objective for occupational health specialists, relying on the burnout construct to attain this objective may be ill-advised. Indeed, there is a significant discrepancy between the popularity of the burnout construct and the validity of burnout research. As shown in the present article, (a) what constitutes a case of burnout remains unclear, (b) the basic conceptualization and operationalization of burnout are ill-aligned, (c) burnout is unlikely to be the specifically job-induced syndrome that it has been posited to be, and (d) the discriminant validity of the burnout construct has not been established. Little progress has been made in the resolution of these fundamental problems despite decades of sustained research on burnout. The lack of validity of burnout undercuts research results

\footnotetext{
${ }^{3}$ The Depersonalization subscale's items were as closely related to that factor as they were to a separate Depersonalization factor. The items of the (Reduced) Personal Accomplishment subscale loaded more substantially on a (Reduced) Personal Accomplishment factor than on the first factor. This latter result is not surprising in view of the problematic operationalization of (reduced) personal accomplishment in the MBI (Schaufeli \& Salanova, 2007)

${ }^{4}$ The DSM-5 replaced the term subtype with the term features. We used the term subtype interchangeably with the term features for ease of exposition.
} 
bearing on the construct. Ultimately, the shaky foundation of the research on burnout undermines the ability of public health policymakers to produce authoritative recommendations.

To more accurately and comprehensively deal with the issue of unresolvable stress at work, occupational health specialists may need to shift their focus from burnout to job-related depression. From this perspective, an important goal for future research would be to establish the prevalence of job-related depression across occupations and geographic areas (Bianchi \& Laurent, 2017; Laurent \& Bianchi, in press); although depression among workers has been investigated (Mata et al., 2015), the specific issue of jobrelated depression has been neglected. To follow up job-related depression in time, it is crucial that assessments be performed at regular intervals (e.g., every year), using identical measurement systems (Laurent \& Bianchi, 2017).

Turning to job-related depression offers occupational health specialists a credible way out of the "burnout impasse." Because the duration of untreated depression bears heavily on the prognosis of the illness (Hung, Liu, \& Yang, 2017), it may be wise to operate such a turnaround rapidly. Should occupational health specialists continue to rely on the burnout construct, we invite them to give priority to the resolution of the major problems affecting their entity of interest. In view of the state of burnout research, the status quo does not appear as a viable option.

\section{References}

Ahola, K., Hakanen, J., Perhoniemi, R., \& Mutanen, P. (2014). Relationship between burnout and depressive symptoms: A study using the person-centred approach. Burnout Research, 1, 29-37. http://dx.doi.org/ 10.1016/j.burn.2014.03.003

Ahola, K., Honkonen, T., Virtanen, M., Kivimäki, M., Isometsä, E., Aromaa, A., \& Lönnqvist, J. (2007). Interventions in relation to occupational burnout: The population-based health 2000 study. Journal of Occupational and Environmental Medicine, 49, 943-952. http://dx.doi.org/10 .1097/JOM.0b013e31813736e3

Ahola, K., Toppinen-Tanner, S., \& Seppänen, J. (2017). Interventions to alleviate burnout symptoms and to support return to work among employees with burnout: Systematic review and meta-analysis. Burnout Research, 4, 1-11.

American Psychiatric Association. (2013). Diagnostic and statistical manual of mental disorders (5th ed.). Washington, DC: Author.

Angermeyer, M. C., Millier, A., Rémuzat, C., Refaï, T., \& Toumi, M. (2013). Attitudes and beliefs of the French public about schizophrenia and major depression: Results from a vignette-based population survey. BMC Psychiatry, 13, 313. http://dx.doi.org/10.1186/1471-244X-13-313

Balon, R. (2017). What about burnout? Annals of Clinical Psychiatry, 29, $81-82$.

Beck, A. T., \& Alford, B. A. (2009). Depression: Causes and treatment (2nd ed.). Philadelphia, PA: University of Pennsylvania Press.

Bianchi, R. (2015). What is "severe burnout" and can its prevalence be assessed? Intensive Care Medicine, 41, 166. http://dx.doi.org/10.1007/ s00134-014-3534-y

Bianchi, R., \& Brisson, R. (in press). Burnout and depression: Causal attributions and construct overlap. Journal of Health Psychology.

Bianchi, R., \& Laurent, E. (2017). Editorial commentary: Burnout in cardiology_-going to the heart of the misunderstanding. Trends in Cardiovascular Medicine. Advance online publication. http://dx.doi.org/ 10.1016/j.tcm.2017.07.008

Bianchi, R., Schonfeld, I. S., \& Laurent, E. (2014). Is burnout a depressive disorder? A re-examination with special focus on atypical depression.
International Journal of Stress Management, 21, 307-324. http://dx.doi .org/10.1037/a0037906

Bianchi, R., Schonfeld, I. S., \& Laurent, E. (2015a). Burnout: Absence of binding diagnostic criteria hampers prevalence estimates. International Journal of Nursing Studies, 52, 789-790. http://dx.doi.org/10.1016/j .ijnurstu.2014.12.008

Bianchi, R., Schonfeld, I. S., \& Laurent, E. (2015b). Burnout-depression overlap: A review. Clinical Psychology Review, 36, 28-41. http://dx .doi.org/10.1016/j.cpr.2015.01.004

Bianchi, R., Schonfeld, I. S., \& Laurent, E. (2015c). Is burnout separable from depression in cluster analysis? A longitudinal study. Social Psychiatry and Psychiatric Epidemiology, 50, 1005-1011. http://dx.doi.org/ 10.1007/s00127-014-0996-8

Bianchi, R., Schonfeld, I. S., \& Laurent, E. (2015d). Is it time to consider the "burnout syndrome" a distinct illness? Frontiers in Public Health, 3, 158. http://dx.doi.org/10.3389/fpubh.2015.00158

Bianchi, R., Schonfeld, I. S., \& Laurent, E. (2016a). The "burnout" construct: An inhibitor of public health action? Critical Care Medicine, 44, e1252-e1253. http://dx.doi.org/10.1097/CCM.0000000000002032

Bianchi, R., Schonfeld, I. S., \& Laurent, E. (2016b). The dead end of current research on burnout prevalence. Journal of the American College of Surgeons, 223, 424-425. http://dx.doi.org/10.1016/j.jamcollsurg .2016 .05 .012

Bianchi, R., Schonfeld, I. S., \& Laurent, E. (2017a). A neglected problem in burnout research. Academic Medicine. Advance online publication. Retrieved from https://www.researchgate.net/publication/319987597_ A_neglected_problem_in_burnout_research_Impact_Factor_5255

Bianchi, R., Schonfeld, I. S., \& Laurent, E. (2017b). Burnout or depression: Both individual and social issue. The Lancet, 390, 230. http://dx.doi.org/ 10.1016/S0140-6736(17)31606-9

Bianchi, R., Schonfeld, I. S., \& Laurent, E. (2017c). Burnout symptoms: Depressive manifestations under psychosocial labels? Asia-Pacific Psychiatry, 9, e12280. http://dx.doi.org/10.1111/appy.12280

Bianchi, R., Schonfeld, I. S., \& Laurent, E. (2017d). Physician burnout is better conceptualised as depression. The Lancet, 389, 1397-1398. http:// dx.doi.org/10.1016/S0140-6736(17)30897-8

Bianchi, R., Schonfeld, I. S., Vandel, P., \& Laurent, E. (2017). On the depressive nature of the "burnout syndrome": A clarification. European Psychiatry, 41, 109-110. http://dx.doi.org/10.1016/j.eurpsy.2016.10 .008

Bianchi, R., Truchot, D., Laurent, E., Brisson, R., \& Schonfeld, I. S. (2014). Is burnout solely job-related? A critical comment. Scandinavian Journal of Psychology, 55, 357-361. http://dx.doi.org/10.1111/sjop .12119

Bianchi, R., Verkuilen, J., Brisson, R., Schonfeld, I. S., \& Laurent, E. (2016). Burnout and depression: Label-related stigma, help-seeking, and syndrome overlap. Psychiatry Research, 245, 91-98. http://dx.doi.org/ 10.1016/j.psychres.2016.08.025

Boerema, A. M., Kleiboer, A., Beekman, A. T. F., van Zoonen, K., Dijkshoorn, H., \& Cuijpers, P. (2016). Determinants of help-seeking behavior in depression: A cross-sectional study. BMC Psychiatry, 16, 78. http://dx.doi.org/10.1186/s12888-016-0790-0

Bradley, B. P., Mogg, K., \& Lee, S. C. (1997). Attentional biases for negative information in induced and naturally occurring dysphoria. Behaviour Research and Therapy, 35, 911-927. http://dx.doi.org/10 .1016/S0005-7967(97)00053-3

Breier, A., Albus, M., Pickar, D., Zahn, T. P., Wolkowitz, O. M., \& Paul, S. M. (1987). Controllable and uncontrollable stress in humans: Alterations in mood and neuroendocrine and psychophysiological function. The American Journal of Psychiatry, 144, 1419-1425. http://dx.doi.org/ 10.1176/ajp.144.11.1419

Brisson, R., \& Bianchi, R. (2017). On the inconsistency of burnout conceptualization and measurement. Journal of the American College of Surgeons, 224, 87. http://dx.doi.org/10.1016/j.jamcollsurg.2016.09.006 
Brown, G. W., \& Harris, T. (1978). Social origins of depression: A study of psychiatric disorder in women. New York, NY: Free Press.

Campbell, D. T., \& Fiske, D. W. (1959). Convergent and discriminant validation by the multitrait-multimethod matrix. Psychological Bulletin, 56, 81-105. http://dx.doi.org/10.1037/h0046016

Caseras, X., Garner, M., Bradley, B. P., \& Mogg, K. (2007). Biases in visual orienting to negative and positive scenes in dysphoria: An eye movement study. Journal of Abnormal Psychology, 116, 491-497. http://dx.doi.org/10.1037/0021-843X.116.3.491

Center, C., Davis, M., Detre, T., Ford, D. E., Hansbrough, W., Hendin, H., .. . Silverman, M. M. (2003). Confronting depression and suicide in physicians: A consensus statement. Journal of the American Medical Association, 289, 3161-3166. http://dx.doi.org/10.1001/jama.289.23 .3161

Cox, T., Tisserand, M., \& Taris, T. (2005). The conceptualization and measurement of burnout: Questions and directions. Work and Stress, 19, 187-191. http://dx.doi.org/10.1080/02678370500387109

Cronbach, L. J., \& Meehl, P. E. (1955). Construct validity in psychological tests. Psychological Bulletin, 52, 281-302. http://dx.doi.org/10.1037/ h0040957

Cuijpers, P., van Straten, A., \& Warmerdam, L. (2007). Behavioral activation treatments of depression: A meta-analysis. Clinical Psychology Review, 27, 318-326. http://dx.doi.org/10.1016/j.cpr.2006.11.001

Danhof-Pont, M. B., van Veen, T., \& Zitman, F. G. (2011). Biomarkers in burnout: A systematic review. Journal of Psychosomatic Research, 70, 505-524. http://dx.doi.org/10.1016/j.jpsychores.2010.10.012

Dohrenwend, B. P. (1979). Stressful life events and psychopathology: Some issues of theory and method. In J. E. Barrett, E. M. Rose, \& G. L. Klerman (Eds.), Stress and mental disorder (pp. 1-15). New York, NY: Raven.

Doulougeri, K., Georganta, K., \& Montgomery, A. (2016). "Diagnosing" burnout among healthcare professionals: Can we find consensus? Cogent Medicine, 3, 1. http://dx.doi.org/10.1080/2331205X.2016.1237605

Dreison, K. C., Luther, L., Bonfils, K. A., Sliter, M. T., McGrew, J. H., \& Salyers, M. P. (2016). Job burnout in mental health providers: A metaanalysis of 35 years of intervention research. Journal of Occupational Health Psychology. Advance online publication. http://dx.doi.org/10 $.1037 /$ ocp0000047

Elmore, L. C., Jeffe, D. B., Jin, L., Awad, M. M., \& Turnbull, I. R. (2016). National survey of burnout among US general surgery residents. Journal of the American College of Surgeons, 223, 440-451. http://dx.doi.org/ 10.1016/j.jamcollsurg.2016.05.014

Epstein, R. M., \& Privitera, M. R. (2016). Doing something about physician burnout. The Lancet, 388, 2216-2217. http://dx.doi.org/10.1016/ S0140-6736(16)31332-0

Fogarty, G. J., \& Perera, H. N. (2016). Resilience: Distinct construct or conglomerate of existing traits? Industrial and Organizational Psychology: Perspectives on Science and Practice, 9, 422-429. http://dx.doi .org/10.1017/iop.2016.33

Freudenberger, H. J. (1974). Staff burnout. Journal of Social Issues, 30, 159-165. http://dx.doi.org/10.1111/j.1540-4560.1974.tb00706.x

Fried, E. I., Nesse, R. M., Guille, C., \& Sen, S. (2015). The differential influence of life stress on individual symptoms of depression. Acta Psychiatrica Scandinavica, 131, 465-471. http://dx.doi.org/10.1111/ acps. 12395

Garrouste-Orgeas, M., Perrin, M., Soufir, L., Vesin, A., Blot, F., Maxime, V., . . . Timsit, J.-F. (2015). The Iatroref study: Medical errors are associated with symptoms of depression in ICU staff but not burnout or safety culture. Intensive Care Medicine, 41, 273-284. http://dx.doi.org/ 10.1007/s00134-014-3601-4

Gauche, C., de Beer, L. T., \& Brink, L. (2017). Exploring demands from the perspective of employees identified as being at risk of burnout. International Journal of Qualitative Studies on Health and Well-Being, 12, 1361783. http://dx.doi.org/10.1080/17482631.2017.1361783
Gilbert, P. (2006). Evolution and depression: Issues and implications. Psychological Medicine, 36, 287-297. http://dx.doi.org/10.1017/ S0033291705006112

Gold, K. J., Andrew, L. B., Goldman, E. B., \& Schwenk, T. L. (2016). "I would never want to have a mental health diagnosis on my record": A survey of female physicians on mental health diagnosis, treatment, and reporting. General Hospital Psychiatry, 43, 51-57. http://dx.doi.org/10 .1016/j.genhosppsych.2016.09.004

Gold, P. W., \& Chrousos, G. P. (2002). Organization of the stress system and its dysregulation in melancholic and atypical depression: High vs. low CRH/NE states. Molecular Psychiatry, 7, 254-275. http://dx.doi .org/10.1038/sj.mp.4001032

Gotlib, I. H., Yue, D. N., \& Joormann, J. (2005). Selective attention in dysphoric individuals: The role of affective interference and inhibition. Cognitive Therapy and Research, 29, 417-432. http://dx.doi.org/10 1007/s10608-005-5753-6

Hakanen, J. J., \& Bakker, A. B. (2017). Born and bred to burn out: A life-course view and reflections on job burnout. Journal of Occupational Health Psychology, 22, 354-364. http://dx.doi.org/10.1037/ocp0000053

Halbesleben, J. R. B., \& Demerouti, E. (2005). The construct validity of an alternative measure of burnout: Investigating the English translation of the Oldenburg Burnout Inventory. Work and Stress, 19, 208-220. http:// dx.doi.org/10.1080/02678370500340728

Hallsten, L., Josephson, M., \& Torgén, M. (2005). Performance-based self-esteem: A driving force in burnout processes and its assessment (NR 2005:4). Stockholm, Sweden: National Institute for Working Life.

Haslam, N., Holland, E., \& Kuppens, P. (2012). Categories versus dimensions in personality and psychopathology: A quantitative review of taxometric research. Psychological Medicine, 42, 903-920. http://dx.doi .org/10.1017/S0033291711001966

Hung, C.-I., Liu, C.-Y., \& Yang, C.-H. (2017). Untreated duration predicted the severity of depression at the two-year follow-up point. PLoS ONE, 12, e0185119. http://dx.doi.org/10.1371/journal.pone.0185119

Ilardi, S. S. (2009). The depression cure: The 6-step program to beat depression without drugs. Cambridge, MA: Da Capo Press.

Judd, L. L., Schettler, P. J., Coryell, W., Akiskal, H. S., \& Fiedorowicz, J. G. (2013). Overt irritability/anger in unipolar major depressive episodes: Past and current characteristics and implications for long-term course. Journal of the American Medical Association Psychiatry, 70 1171-1180. http://dx.doi.org/10.1001/jamapsychiatry.2013.1957

Kim, H., \& Eaton, N. R. (2015). The hierarchical structure of common mental disorders: Connecting multiple levels of comorbidity, bifactor models, and predictive validity. Journal of Abnormal Psychology, 124, 1064-1078. http://dx.doi.org/10.1037/abn0000113

Kristensen, T. S., Borritz, M., Villadsen, E., \& Christensen, K. B. (2005). The Copenhagen Burnout Inventory: A new tool for the assessment of burnout. Work and Stress, 19, 192-207. http://dx.doi.org/10.1080/ 02678370500297720

Kroenke, K., \& Spitzer, R. L. (2002). The PHQ-9: A new depression diagnostic and severity measure. Psychiatric Annals, 32, 509-515. http://dx.doi.org/10.3928/0048-5713-20020901-06

Laborit, H. (1986). L'inhibition de l'action (2nd ed.). Paris, France: Masson.

Lamers, F., Vogelzangs, N., Merikangas, K. R., de Jonge, P., Beekman, A. T. F., \& Penninx, B. W. J. H. (2013). Evidence for a differential role of HPA-axis function, inflammation and metabolic syndrome in melancholic versus atypical depression. Molecular Psychiatry, 18, 692-699. http://dx.doi.org/10.1038/mp.2012.144

Laurent, E., \& Bianchi, R. (2017). Assessing depression among new fathers. Journal of the American Medical Association Psychiatry, 74, 855. http://dx.doi.org/10.1001/jamapsychiatry.2017.1391

Laurent, E., \& Bianchi, R. (in press). Humeur, burnout et dépression : enjeux sociétaux, constats scientifiques et stratégies managériales et politiques [Mood, burnout, and depression: Societal challenges, scien- 
tific facts, and managerial and political strategies]. In F. Jamet, J. Baratgin, \& C. Puigelier (Eds.), Burnout, droit et cognition [Burnout, law, and cognition]. Paris, France: Mare \& Martin (Collection Science et Droit).

Le, H., Schmidt, F. L., Harter, J. K., \& Lauver, K. J. (2010). The problem of empirical redundancy of constructs in organizational research: An empirical investigation. Organizational Behavior and Human Decision Processes, 112, 112-125. http://dx.doi.org/10.1016/j.obhdp.2010.02.003

Lehr, D., Koch, S., \& Hillert, A. (2010). Where is (im)balance? Necessity and construction of evaluated cut-off points for effort-reward imbalance and overcommitment. Journal of Occupational and Organizational Psychology, 83, 251-261. http://dx.doi.org/10.1348/096317909X406772

Leiter, M. P., \& Durup, J. (1994). The discriminant validity of burnout and depression: A confirmatory factor analytic study. Anxiety, Stress, and Coping, 7, 357-373. http://dx.doi.org/10.1080/10615809408249357

Leiter, M. P., \& Maslach, C. (2016). Latent burnout profiles: A new approach to understanding the burnout experience. Burnout Research, 3, 89-100. http://dx.doi.org/10.1016/j.burn.2016.09.001

Liu, R. T. (2016). Taxometric evidence of a dimensional latent structure for depression in an epidemiological sample of children and adolescents. Psychological Medicine, 46, 1265-1275. http://dx.doi.org/10.1017/ S0033291715002792

Maricuţoiu, L. P., Sava, F. A., \& Butta, O. (2016). The effectiveness of controlled interventions on employees' burnout: A meta-analysis. Journal of Occupational and Organizational Psychology, 89, 1-27. http:// dx.doi.org/10.1111/joop.12099

Marsh, H. W., Morin, A. J., Parker, P. D., \& Kaur, G. (2014). Exploratory structural equation modeling: An integration of the best features of exploratory and confirmatory factor analysis. Annual Review of Clinical Psychology, 10, 85-110. http://dx.doi.org/10.1146/annurev-clinpsy032813-153700

Martin, J. K., Blum, T. C., Beach, S. R. H., \& Roman, P. M. (1996). Subclinical depression and performance at work. Social Psychiatry and Psychiatric Epidemiology, 31, 3-9.

Martin, L. A., Neighbors, H. W., \& Griffith, D. M. (2013). The experience of symptoms of depression in men vs women: Analysis of the National Comorbidity Survey Replication. Journal of the American Medical Association Psychiatry, 70, 1100-1106. http://dx.doi.org/10.1001/ jamapsychiatry.2013.1985

Maslach, C. (1976). Burned-out. Human Behavior, 5, 16-22.

Maslach, C., \& Jackson, S. E. (1981). The measurement of experienced burnout. Journal of Organizational Behavior, 2, 99-113. http://dx.doi .org/10.1002/job.4030020205

Maslach, C., Jackson, S. E., \& Leiter, M. P. (1996). Maslach Burnout Inventory manual (3rd ed.). Palo Alto, CA: Consulting Psychologists Press.

Maslach, C., \& Leiter, M. P. (2008). Early predictors of job burnout and engagement. Journal of Applied Psychology, 93, 498-512. http://dx.doi .org/10.1037/0021-9010.93.3.498

Maslach, C., \& Leiter, M. P. (2010). Burnout. In G. Fink (Ed.), Stress consequences: Mental, neuropsychological and socioeconomic (pp. 726-729). New York, NY: Academic Press.

Maslach, C., Schaufeli, W. B., \& Leiter, M. P. (2001). Job burnout. Annual Review of Psychology, 52, 397-422. http://dx.doi.org/10.1146/annurev .psych.52.1.397

Mata, D. A., Ramos, M. A., Bansal, N., Khan, R., Guille, C., Di Angelantonio, E., \& Sen, S. (2015). Prevalence of depression and depressive symptoms among resident physicians: A systematic review and metaanalysis. Journal of the American Medical Association, 314, 2373-2383. http://dx.doi.org/10.1001/jama.2015.15845

Matheson, K., \& Anisman, H. (2003). Systems of coping associated with dysphoria, anxiety and depressive illness: A multivariate profile perspective. Stress: The International Journal on the Biology of Stress, 6, 223-234. http://dx.doi.org/10.1080/10253890310001594487
McEwen, B. S. (2004). Protection and damage from acute and chronic stress: Allostasis and allostatic overload and relevance to the pathophysiology of psychiatric disorders. Annals of the New York Academy of Sciences, 1032, 1-7. http://dx.doi.org/10.1196/annals.1314.001

Melchior, M., Caspi, A., Milne, B. J., Danese, A., Poulton, R., \& Moffitt, T. E. (2007). Work stress precipitates depression and anxiety in young, working women and men. Psychological Medicine, 37, 1119-1129. http://dx.doi.org/10.1017/S0033291707000414

Nesse, R. M. (2000). Is depression an adaptation? Archives of General Psychiatry, 57, 14-20. http://dx.doi.org/10.1001/archpsyc.57.1.14

Niedhammer, I., Malard, L., \& Chastang, J. F. (2015). Occupational factors and subsequent major depressive and generalized anxiety disorders in the prospective French national SIP study. BMC Public Health, 15, 200. http://dx.doi.org/10.1186/s12889-015-1559-y

Orosz, A., Federspiel, A., Haisch, S., Seeher, C., Dierks, T., \& Cattapan, K. (2017). A biological perspective on differences and similarities between burnout and depression. Neuroscience and Biobehavioral Reviews, 73, 112-122. http://dx.doi.org/10.1016/j.neubiorev.2016.12.005

Orton, P., Orton, C., \& Pereira Gray, D. (2012). Depersonalised doctors: A cross-sectional study of 564 doctors, 760 consultations and 1876 patient reports in U.K. general practice. British Medical Journal Open, 2, e000274. http://dx.doi.org/10.1136/bmjopen-2011-000274

Palmer, C. E. (1983). A note about paramedics' strategies for dealing with death and dying. Journal of Occupational Psychology, 56, 83-86. http:// dx.doi.org/10.1111/j.2044-8325.1983.tb00114.x

Panagioti, M., Panagopoulou, E., Bower, P., Lewith, G., Kontopantelis, E., Chew-Graham, C., . . . Esmail, A. (2017). Controlled interventions to reduce burnout in physicians: A systematic review and meta-analysis. Journal of the American Medical Association Internal Medicine, 177, 195-205. http://dx.doi.org/10.1001/jamainternmed.2016.7674

Pines, A. M. (1987). Marriage burnout. Psychotherapy in Private Practice, $5,31-44$.

Pizzagalli, D. A. (2014). Depression, stress, and anhedonia: Toward a synthesis and integrated model. Annual Review of Clinical Psychology, 10, 393-423. http://dx.doi.org/10.1146/annurev-clinpsy-050212-185606

Prisciandaro, J. J., \& Tolliver, B. K. (2015). Evidence for the continuous latent structure of mania and depression in out-patients with bipolar disorder: Results from the systematic treatment enhancement program for bipolar disorder (STEP-BD). Psychological Medicine, 45, 25952603. http://dx.doi.org/10.1017/S0033291715000513

Pryce, C. R., Azzinnari, D., Spinelli, S., Seifritz, E., Tegethoff, M., \& Meinlschmidt, G. (2011). Helplessness: A systematic translational review of theory and evidence for its relevance to understanding and treating depression. Pharmacology and Therapeutics, 132, 242-267. http://dx.doi.org/10.1016/j.pharmthera.2011.06.006

Qiao, H., \& Schaufeli, W. B. (2011). The convergent validity of four burnout measures in a Chinese sample: A confirmatory factor-analytic approach. Applied Psychology: An International Review, 60, 87-111. http://dx.doi.org/10.1111/j.1464-0597.2010.00428.x

Richards, D. A., Ekers, D., McMillan, D., Taylor, R. S., Byford, S., Warren, F. C., . . . Finning, K. (2016). Cost and outcome of behavioural activation versus cognitive behavioural therapy for depression (COBRA): A randomised, controlled, non-inferiority trial. The Lancet, 388, 871-880. http://dx.doi.org/10.1016/S0140-6736(16)31140-0

Roberts, J. E., Gilboa, E., \& Gotlib, I. H. (1998). Ruminative response style and vulnerability to episodes of dysphoria: Gender, neuroticism, and episode duration. Cognitive Therapy and Research, 22, 401-423. http:// dx.doi.org/10.1023/A:1018713313894

Rose, A., Duschinsky, R., \& Macnaughton, J. (2017). Cynicism as a strategic virtue. The Lancet, 389, 692-693. http://dx.doi.org/10.1016/ S0140-6736(17)30349-5

Rössler, W., Hengartner, M. P., Ajdacic-Gross, V., \& Angst, J. (2015). Predictors of burnout: Results from a prospective community study. 
European Archives of Psychiatry and Clinical Neuroscience, 265, 1925. http://dx.doi.org/10.1007/s00406-014-0512-x

Rusch, L. C., Kanter, J. W., \& Brondino, M. J. (2009). A comparison of contextual and biomedical models of stigma reduction for depression with a nonclinical undergraduate sample. Journal of Nervous and Mental Disease, 197, 104-110. http://dx.doi.org/10.1097/NMD.0b013e318 $192416 \mathrm{f}$

Sapolsky, R. M. (2004). Why zebras don't get ulcers (3rd ed.). New York, NY: Holt Paperbacks.

Schaufeli, W. B. (2017). Burnout: A short socio-cultural history. In S. Neckel, A. K. Schaffner, \& G. Wagner (Eds.), Burnout, fatigue, exhaustion: An interdisciplinary perspective on a modern affliction (pp. 105127). Cham, Switzerland: Palgrave Macmillan. http://dx.doi.org/10 .1007/978-3-319-52887-8_5

Schaufeli, W. B., \& Enzmann, D. (1998). The burnout companion to study and practice: A critical analysis. London, United Kingdom: Taylor \& Francis.

Schaufeli, W. B., Leiter, M. P., \& Maslach, C. (2009). Burnout: 35 years of research and practice. The Career Development International, 14, 204-220. http://dx.doi.org/10.1108/13620430910966406

Schaufeli, W. B., \& Salanova, M. (2007). Efficacy or inefficacy, that's the question: Burnout and work engagement, and their relationships with efficacy beliefs. Anxiety, Stress, and Coping: An International Journal, 20, 177-196. http://dx.doi.org/10.1080/10615800701217878

Schears, R. M. (2017). Defining physician burnout, and differentiating between burnout and depression-II. Mayo Clinic Proceedings, 92, 1455-1456. http://dx.doi.org/10.1016/j.mayocp.2017.07.006

Schonfeld, I. S. (2001). Stress in 1st-year women teachers: The context of social support and coping. Genetic, Social, and General Psychology Monographs, 127, 133-168.

Schonfeld, I. S., \& Bianchi, R. (2016). Burnout and depression: Two entities or one? Journal of Clinical Psychology, 72, 22-37. http://dx.doi .org/10.1002/jclp.22229

Schonfeld, I. S., Laurent, E., \& Bianchi, R. (2017). Burnout research: Eyes wide shut. Critical Care Medicine. Advance online publication. Retrieved from https://www.researchgate.net/publication/319943326_ Burnout_research_Eyes_wide_shut_Impact_Factor_7050

Schonfeld, I. S., Verkuilen, J., \& Bianchi, R. (2017, June 7-10). Confirmatory factor analysis of burnout and depressive symptoms. 12th Inter- national Conference on Occupational Stress and Health, Minneapolis $\mathrm{MN}$

Seligman, M. E. P. (1975). Helplessness: On depression, development, and death. San Francisco, CA: Freeman.

Shanafelt, T. D., Hasan, O., Dyrbye, L. N., Sinsky, C., Satele, D., Sloan, J., $\&$ West, C. P. (2015). Changes in burnout and satisfaction with work-life balance in physicians and the general US working population between 2011 and 2014. Mayo Clinic Proceedings, 90, 1600-1613. http://dx.doi .org/10.1016/j.mayocp.2015.08.023

Shirom, A. (2005). Reflections on the study of burnout. Work and Stress: An International Journal of Work, Health and Organizations, 19, 263 270. http://dx.doi.org/10.1080/02678370500376649

Strack, S., \& Coyne, J. C. (1983). Social confirmation of dysphoria: Shared and private reactions to depression. Journal of Personality and Social Psychology, 44, 798-806. http://dx.doi.org/10.1037/0022-3514.44.4 .798

Taris, T. W. (2006). Is there a relationship between burnout and objective performance? A critical review of 16 studies. Work and Stress, 20, 316-334. http://dx.doi.org/10.1080/02678370601065893

Wang, J., Patten, S. B., Currie, S., Sareen, J., \& Schmitz, N. (2012). A population-based longitudinal study on work environmental factors and the risk of major depressive disorder. American Journal of Epidemiology, 176, 52-59. http://dx.doi.org/10.1093/aje/kwr473

West, C. P., Dyrbye, L. N., Erwin, P. J., \& Shanafelt, T. D. (2016) Interventions to prevent and reduce physician burnout: A systematic review and meta-analysis. The Lancet, 388, 2272-2281. http://dx.doi .org/10.1016/S0140-6736(16)31279-X

Willner, P., Scheel-Krüger, J., \& Belzung, C. (2013). The neurobiology of depression and antidepressant action. Neuroscience and Biobehavioral Reviews, 37, 2331-2371. http://dx.doi.org/10.1016/j.neubiorev.2012.12 .007

Winwood, P. C., \& Winefield, A. H. (2004). Comparing two measures of burnout among dentists in Australia. International Journal of Stress Management, 11, 282-289. http://dx.doi.org/10.1037/1072-5245.11.3 .282

Received March 14, 2017

Revision received October 2, 2017

Accepted October 12, 2017 